\title{
Comunicação em Ouvidoria: um caso de prática organizacional
}

Ombudsman Communication: a case of organizational practice

Comunicación del Defensor del Pueblo: un caso de práctica organizativa

\section{(5) Flávia de Almeida Moura}

- Doutora em Comunicação pela Pontifícia Universidade Católica do Rio Grande do Sul (PUC-RS).

- Professora do Departamento deComunicação e do ProgramadePós-Graduação em Comunicação/ Mestrado Profissional da Universidade Federal do Maranhão (UFMA).

- E-mail: flavia.moura@ufma.br

\section{(9) Pedro Germano Nobre Neto}

- Mestrando pelo Programa de Pós-Graduação em Comunicação/Mestrado Profissional da UFMA.

- Graduado em Relações Públicas pela UFMA.

- E-mail: pedro_germano003@hotmail.com

\section{(9) Bruna Rafaela Almeida da Costa}

- Mestra em Comunicação e Cultura pela Faculdade de Informação e Comunicação (FIC) da Universidade Federal de Goiás (UFG).

- Graduada em Comunicação Social/Habilitação em Rádio e TV pela Universidade Federal do Maranhão (UFMA).

- Atualmente é Social Media e Professora de Graduação e Pós-Graduação da Faculdade Laboro.

- E-mail: brunaalmeida87@gmail.com 


\section{Resumo}

Este artigo traz uma problematização acerca da temática "comunicação e ouvidoria pública" ao apresentar um estudo em andamento que busca compreender de que formas a rede de ouvidorias da Empresa Brasileira de Serviços Hospitalares (EBSERH) desenvolve práticas comunicativas sob a ótica da tríade: registro de manifestação, pesquisa de satisfação e serviço de informação ao cidadão; e como tais práticas podem ser analisadas no contexto da comunicação organizacional. A metodologia é qualitativa, com informações advindas de questionário, entrevistas e observação participante.

\section{PALAVRAS-CHAVE: OUVIDORIA PÚBLICA •PRÁTICAS COMUNICATIVAS•COMUNICAÇÃO ORGANIZACIONAL.}

\section{Abstract}

This article questions the matter of communication and public ombudsman services by presenting an ongoing study that analyzes how the Ombudsman Network of the Brazilian Hospital Services Company (EBSERH) develops communicative practices from the perspective of the triad registration of manifestation, satisfaction survey and citizen information service and how such practices can be analyzed in the context of organizational communication. The methodology adopted is qualitative, with data from questionnaire, interviews and participant observation.

\section{KEYWORDS: PUBLIC OMBUDSMAN・COMMUNICATIVE PRACTICES・ORGANIZATIONAL COMMUNICATION}

\section{Resumen}

Este artículo plantea el tema "comunicación y defensoría del pueblo público" al presentar un estudio en curso que busca comprender cómo la Red de Defensoría del Pueblo de la Empresa Brasileña de Servicios Hospitalarios (EBSERH) desarrolla prácticas comunicativas desde la perspectiva de la tríada: registro de manifestación, encuesta de satisfacción y servicio de información ciudadana; y cómo estas prácticas pueden analizarse en el contexto de comunicación organizativa. La metodología es cualitativa, con datos provenientes de cuestionario, entrevistas y observación participante. 
A

década de 1990 apresentou a busca massiva da conscientização do cidadão sobre seus direitos, com discussões exaustivas que culminaram em grandes conquistas para o povo brasileiro. Tais desdobramentos foram resultados da Constituição Federal de 1988, em que o exercício pleno da cidadania foi evidenciado com base nos preceitos jurídicos.

Nessa perspectiva, surgiu o princípio da participação social na administração pública em que 0 \& $3^{0}$ do artigo $37^{0}$ da referida Constituição traz que a lei disciplinará as formas de participação na administração pública, apontando, especialmente, as reclamações relativas à prestação dos serviços públicos em geral, avaliação periódica da qualidade dos serviços e 0 acesso aos registros administrativos e às informações sobre atos de governo (Brasil, 1988).

A partir dessa prerrogativa, destaca-se que a possibilidade de interlocução do cidadão com o Estado, principalmente com a administração pública, caracteriza a institucionalização das ouvidorias.

Nesse cenário, há necessidade de entender a participação social com foco na comunicação, apresentando uma visão do processo comunicativo que dá voz e vez a atores sociais que não tinham um lugar de fala na sociedade, propiciando um avanço democrático e estabelecendo um sistema que exige informação e uma relação mútua do cidadão com o Estado e as instituições.

Assim, o presente artigo traz uma problematização acerca da temática "comunicação e ouvidoria pública" com o intuito de apresentar um estudo em andamento que busca compreender de que formas a Rede de Ouvidorias da Empresa Brasileira de Serviços Hospitalares (EBSERH), responsável pela gestão dos hospitais universitários federais, desenvolve práticas comunicativas sob a ótica da tríade registro de manifestação, pesquisa de satisfação e serviço de informação ao cidadão e como tais práticas podem ser analisadas no contexto da comunicação organizacional.

Para esta análise, é preciso levar em consideração ainda o entendimento de "rede social" enquanto construção de vínculos relacionais entre indivíduos, sendo tal característica relacionada à organização da rede em questão pela atuação coletiva benéfica à funcionalidade das ouvidorias nos hospitais universitários federais, em que são compartilhados conhecimentos, informações e experiências, além da busca pela padronização das atividades e dos processos de trabalhos.

A rede de ouvidorias da EBSERH é formada por um grupo de 39 ouvidores dos hospitais universitários federais, de todas as regiões do Brasil, que utilizam práticas comunicativas no dia a dia, mesmo que não estabelecidas por profissionais da área haja vista que, desse total, menos de cinco são comunicólogos, levando em conta que legalmente não há a exigência de uma formação profissional específica, apesar da necessidade de curso superior.

Portanto, as práticas comunicativas levam em consideração a troca, a interação e a relação entre pessoas, que, alinhadas à produção de sentidos, apresenta aspectos como a representação cidadã e suas mediações. A partir delas, a atividade da ouvidoria se insere na seara da área de comunicação, analisando e avaliando a organização por meio do feedback dos usuários acerca dos serviços oferecidos, podendo, ainda, auxiliar a gestão nas tomadas de decisões e gerenciar as imagens efetivadas a partir da relação estabelecida pela vivência diária junto à instituição. 


\section{OUVIDORIA PÚBLICA COMO PRÁTICA COMUNICATIVA NA EBSERH}

A Constituição Federal de 1988 estabeleceu diversos direitos, espaços públicos de debates e movimentações sociais. Os mecanismos criados possibilitaram a discussão e o aprimoramento de programas e políticas públicas, instituindo a base jurídica que possibilitou a consolidação da democracia brasileira, resultando ainda na participação social na administração pública. (Enap, 2017, p.6).

A ouvidoria é, então, inserida nesse contexto em que decretos e instruções normativas são apresentados a fim de balizar as atividades - 0 que fez com que patamares mais elevados fossem galgados, colaborando para sua conceituação enquanto instituição que auxilia o cidadão em suas relações com o Estado, atuando no processo de diálogo entre o cidadão e a instituição pública para que as manifestações advindas desse processo provocassem a melhoria dos serviços públicos prestados (Brasil, 2012, p.7).

Em 26 de junho de 2017 foi promulgada a lei nำ13.460 que dispõe sobre a participação, proteção e defesa dos direitos dos

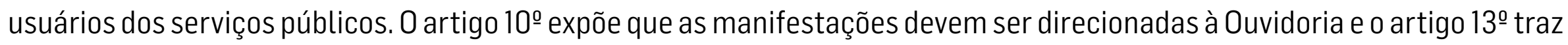
as funções precípuas: promoção da participação do usuário na administração pública; acompanhamento da prestação dos serviços; proposição de aperfeiçoamentos; auxílio na prevenção e correção dos atos e procedimentos; proposição e adoção de medidas para a defesa dos direitos do usuário; recepção, análise e encaminhamento das manifestações dos usuários e promoção e adoção de mediação e conciliação entre o usuário e a instituição pública (Brasil, 2017).

O entendimento desse processo caracteriza as práticas comunicativas existentes nas interfaces dessas categorias, uma vez que a comunicação tem sido identificada pelos seus estudiosos para além das questões instrumentais. " 0 maior desafio para a investigação em comunicação organizacional está em superar as visões tradicionais e contribuir com uma concepção renovada do ambiente mutável das organizações" (Curvello, 2002, p.13).

Portanto, a comunicação, nesse contexto, deve assumir uma perspectiva cidadã, imbuída de sua essência de interação com o outro e de troca de informações, buscando o entendimento e a compreensão para o bem de toda a sociedade (lasbeck, 2006, p.13). Assim, torna-se um processo intermitente de produção de sentidos, que, alinhados aos discursos, favorecem a formação de imagens e de percepções sociais e organizacionais.

Essa comunicação não chega a ser uma força predominante, mas desempenha um papel importante da democratização da informação e da cidadania, tanto no sentido da ampliação do número de canais de informação e na inclusão de novos emissores, como no fato de se constituir em processo educativo, não só pelos conteúdos emitidos, mas pelo envolvimento direto das pessoas no que fazer comunicacional e nos próprios movimentos populares. (Peruzzo, 2007, p.3).

A ouvidoria faz uso de práticas comunicativas ao se tornar tanto representante da instituição perante um usuário quanto representante dos usuários perante a instituição, trabalhando, assim, a receptividade, a escuta qualificada, a codificação de signos e significados, a persuasão, a resolução de conflitos, a oratória, a produção textual, a gestão da imagem institucional e gestão da informação.

Resolver conflitos, tornar a organização aberta, ampliar relações, constituir espaços de fala, manifestar vozes que às vezes são reprimidas, inibir incivilidade no ambiente organizacional, aprender a respeitar pessoas, identificar contextos de manipulação de pessoas; vemos que esses procedimentos buscam o desenvolvimento de uma organização com mais qualidade. Essas respostas evidenciam a ouvidoria como uma possibilidade basilar para as organizações construírem a cidadania no nível microssocial, 
com base no diálogo que legitima a transparência, na busca do entendimento, do relacionamento e do conhecimento das pessoas. (Marchiori, 2010, p.119).

Suas atividades vão além da participação social legalmente instituída. A ouvidoria tem o papel fundamental de transformar em oportunidade as ameaças surgidas do relacionamento da organização com o usuário, humanizando a relação. Para tanto, deve identificar, a partir de cada demanda, a possibilidade de um eventual problema de gestão, contribuindo para a sua solução e apresentando alternativas e/ou informações em busca da melhoria contínua dos serviços prestados.

[...] no contexto das organizações modernas, vê-se aumentar a necessidade de fortalecimento e, em alguns casos, implementação de uma cultura dialógica, que implique em ouvir o que os públicos têm a dizer e expressar feedback, a fim de construir e/ ou revigorar relacionamentos. Uma organização que atingiu plena consciência do valor do "ouvir" possui mecanismos para tornar-se sempre mais receptiva ao que os funcionários e clientes têm a dizer. Assim, age no sentido de entender, compreender a demanda e os anseios desses públicos, por entender que são justamente esses fatores que tornam uma organização dinâmica e mais aberta à inovação. Essa sintonia organizacional é fruto da interlocução organização-público, ou seja, resultado que se pode esperar de um processo de ouvidoria. (Bastos; Marchiori; Moraes, 2012, p.85).

Ao caracterizar a afirmação de que "ouvidoria é comunicação", lasbeck (2010, p.17) afirma que ela "é um texto por excelência, uma vez que é constituída formal e legalmente para representar a organização, mediar relações e executar políticas estratégicas". Já Baldissera (2008, p.47) avalia que se deve "agir potencializando os lugares de escuta para as manifestações da diversidade e fomentar a crítica como necessária para o desenvolvimento e qualificação de processos", evidenciando uma instância relacional da comunicação e estabelecendo a importância do outro em mais um eu em seu lugar de fala, além de agregar valor ao processo comunicativo por meio do uso da empatia e de uma linguagem cidadã e inclusiva como possíveis estratégias.

Nas ouvidorias dos hospitais universitários federais, o usuário tem a possibilidade de dialogar com a instituição, apontando sua insatisfação ou satisfação, elencando pontos a serem melhorados, corrigidos ou potencializados. Ele tem a possibilidade de expor sua realidade e suas angústias em um ambiente formal para que haja um direcionamento institucional daquela situação - considerando que são avaliadas, primeiramente, situações individualizadas, para então colocar a coletividade em cena.

Por essa razão, a receptividade e a escuta qualificada no início do processo se tornam fundamentais, gerando valor ao papel do usuário como ator para a melhoria dos serviços ofertados pela organização. Por outro lado, o feedback das diversas falas promove um conteúdo a ser explorado pela gestão, dando margens às tomadas de decisões em prol dos anseios da sociedade, e não apenas da cabeça dos gestores. A ouvidoria, então, gerencia relacionamentos, participando da gestão e concebendo relações públicas na perspectiva da comunicação organizacional.

Nassar (2006) ajuda a entender melhor essa dinâmica organizacional, que pode, facilmente, ser interpretada em meio à atividade de ouvidoria, haja vista os constantes usuários que buscam o serviço, construindo e desconstruindo imagens da instituição a todo instante a partir do momento relacional vivido.

A comunicação organizacional é meta-organizacional, ela acontece, é desenhada em um ambiente relacional, enredado, em que a empresa ou instituição não é mais o centro, mas é coparticipante. A organização não tem mais o poder de dizer que quer ser percebida de uma forma ou de outra, a partir de uma área de comunicação ou de gestão. Ela será aquilo que a rede relacional perceber; será aquilo que expressará uma intensa negociação e trocas. Essa rede não admite participantes passivos. (Nassar, 2006, p.34). 
Soma-se a essa análise, segundo a Enap (2017, p.9), que a ouvidoria deve ouvir e compreender os diferentes usuários, legitimando suas manifestações; reconhecer as diferenças de cada um, com seus direitos e deveres; qualificar as expectativas em visão geral para oportunidades de melhorias existentes; responder a todos utilizando linguagem simples e compreensível e demonstrar os resultados produzidos, elaborando relatórios gerenciais.

Portanto, há a necessidade do gerenciamento de diversos relacionamentos na tentativa de construir as imagens e a reputação da organização, com a consciência de que riscos podem surgir e de que há necessidade de administrá-los sem que surjam caracterizações deturpadas e, assim, não sejam gerados prejuízos financeiros e/ou sociais.

A comunicação é esse processo em que as imagens, representações são produzidas, trocadas, atualizadas no bojo de relações; esse processo em que sujeitos interlocutores produzem, se apropriam e atualizam permanentemente os sentidos que moldam seu mundo e, em última instância, o próprio mundo. Portanto, o lugar da comunicação (das práticas comunicativas) é um lugar constituinte e o olhar (abordagem) comunicacional é um olhar que busca apreender esse movimento de constituição. (França, 2005, p.23).

No bojo desta discussão, as práticas comunicativas serão evidenciadas a partir da rede de ouvidorias da EBSERH, levando em consideração a caracterização de "rede social" elaborada por Regina Maria Marteleto (2010, p.28) como "uma compreensão da sociedade a partir dos vínculos relacionais entre os indivíduos, os quais reforçariam suas capacidades de atuação, compartilhamento, aprendizagem, captação de recursos e mobilização".

No entanto, tal conceituação vai além, uma vez que o objeto de estudo tem característica organizacional e as redes sociais se desenvolvem em diversas esferas e áreas do conhecimento.

Uma Rede Social é uma estrutura composta por pessoas ou organizações, conectadas por um ou vários tipos de relações, que partilham valores e temas. Uma das características fundamentais de definição das redes é a sua porosidade e abertura, possibilitando relacionamentos horizontais e não hierárquicos entre os participantes. (Bernardo, 2011, p.3)

Na concepção atual, a gestão do tempo e do espaço ganha notoriedade nas redes sociais e os atores envolvidos são imbuídos de um sentimento por objetivos comuns, em que se processa o compartilhamento de informações e de conhecimentos, resultados da integração entre as pessoas - seja em ambiente físico ou virtual.

No caso em questão, os ouvidores dos hospitais universitários federais lançam mão dos dois ambientes, uma vez que há ferramentas tecnológicas que permitem a relação digital constante (grupos de e-mail, WhatsApp, Microsoft Teams e videoconferências), assim como há encontros anuais que possibilitam a discussão de ideias em caráter presencial. Essa dinâmica faz com que os profissionais se complementem, ultrapassando o espaço acadêmico/científico ao formalizar uma rede técnica para o processo de trabalho da ouvidoria, o que aprimora as práticas desenvolvidas na busca pela padronização das ações apesar das particularidades de cada hospital.

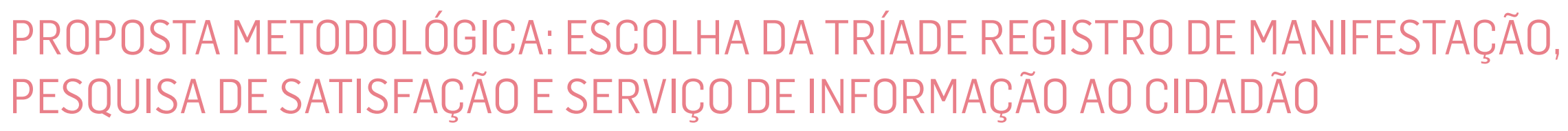

Baseado num procedimento analítico qualitativo em que o interesse não está em determinar parâmetros estatísticos mas sim em dar ênfase aos processos de trabalhos, aos atores e ao contato direto com o objeto da pesquisa por meio das estruturas sociais estabelecidas, este estudo busca analisar uma rede social de ouvidorias como fonte direta de dados e o pesquisador 
como instrumento fundamental, ambos a partir da concepção de que os estudos qualitativos se preocupam com o mundo empírico e seu ambiente natural, tendo o pesquisador contato direto com a realidade estudada (Godoy, 1995).

A pesquisa apresenta um enfoque indutivo com o intuito de corroborar a íntima relação existente entre a comunicação organizacional e as práticas comunicativas da ouvidoria, utilizando-se de um objeto que a compreende toda a rede de ouvidorias da EBSERH. Assim, busca-se uma análise descritiva dos dados com o objetivo de observar, registrar, analisar, compreender e descrever um sistema complexo de significados no contexto da comunicação - com suas características reais, sem manipulálas, a fim de verificar as práticas comunicativas estabelecidas nas referidas ouvidorias. (Manzato; Santos, 2012, p.4).

A análise tem como ponto de partida as informações coletadas por meio de questionário, entrevistas e observação participante, considerando o que Deslauriers e Kérisit (2008, p.140) apontam como descrição: "a etapa de análise consiste em encontrar um sentido para os dados coletados e em demonstrar como eles respondem ao problema de pesquisa que o pesquisador formulou progressivamente". A pesquisa terá ainda como base de análise a consulta de dados secundários de acordo com as literaturas que nortearão as categorias elencadas, além da legislação vigente e do arcabouço documental à disposição da atividade das ouvidorias na EBSERH.

Para tanto, investigar as ações realizadas pelas ouvidorias em questão evidenciará o enfoque da comunicação organizacional, relacionado-as às exemplificações de situações reais que culminaram em resultados para os usuários e para a organização. A proposta é de que os ouvidores correlacionem práticas comunicativas com as suas atividades diárias a partir da tríade apontada, que é o lugar de fala dos vários "eus" existentes.

Neste sentido, o tratamento analítico do material recolhido em questionários, entrevistas, observação direta e dados secundários será feito para estabelecer conclusões que nortearão o artefato do objeto deste estudo. A partir da resposta ao problema indicado, será elaborado um manual de comunicação como ato normativo para as práticas comunicativas desenvolvidas pela rede de ouvidorias da EBSERH, que será apresentado à ouvidoria geral da empresa para aprovação e posterior disponibilização aos ouvidores.

\section{ANÁLISES PRELIMINARES}

lasbeck (2012, p.33-34) afirma que, na realidade brasileira, o ouvidor, além de suas funções precípuas de participação social, deve planejar, controlar, supervisionar, coordenar e avaliar os trabalhos da ouvidoria que perpassam aadministração dos fluxos de informação, o tratamento das manifestações, a supervisão das tarefas diárias à luz da economicidade e otimização de recursos, as percepções sistêmicas do cotidiano da instituição alinhadas à harmonia da comunicação estabelecida na instituição perante seus usuários e o resguardo do direito sobre o sigilo das informações sensíveis, entre outros. (lasbeck, 2012, p.33-34)

Dessa forma, a partir da tríade já mencionada e fazendo uma analogia, afirma-se que o Registro de Manifestação é o coração da ouvidoria, a matéria-prima diária da participação social e do processo comunicativo por ser o momento em que o usuário busca a instituição para dialogar.

A manifestação é parte integrante da atividade da ouvidoria. A quem pense que ser ouvidor está relacionado apenas ao ouvir, engana-se. Acolher, receber bem, escutar, dar atenção, interpretar, tentar se colocar no lugar do outro, valorizar a sua fala ou o texto escrito, conversar e buscar um entendimento para transformar o relato em uma manifestação de ouvidoria são etapas e funções fundamentais. 
Faz-se uso ainda da produção textual com o intuito de registrar a demanda no sistema para envio aos devidos responsáveis. Produzir um bom texto que respeite as regras gramaticais facilita o processo de entendimento de todos os envolvidos. Os resposáveis institucionais avaliarão a demanda para a possível solução do problema, a correção de processos, a maximização de ações e o posicionamento da ouvidoria para o repasse de informações ao usuário. A resposta conclusiva é um posicionamento institucional, que pode ser avaliada em sua resolutividade, qualidade e temporalidade.

A resposta aos usuários é uma atividade de relevância e não deve ser tratada como simples tramitações no cerne da comunicação administrativa, mas como um processo comunicativo para além dos muros da organização, que pode trilhar outros caminhos a partir da chegada da informação nas mãos de um usuário.

Destaca-se ainda a necessidade de buscar responder conforme o relato apresentado, levando em consideração o outro na perspectiva de sua importância enquanto pessoa, utilizando palavras de fácil entendimento, com uma linguagem cidadã e elementos inclusivos, sem utilização de termos pejorativos. "Cuidar da qualidade da resposta é uma atitude mercadologicamente correta e, normalmente, eficaz" (lasbeck, 2012, p.49)

No ínterim do processo, tem-se ainda a categorização da manifestação (denúncia, elogio, reclamação, solicitação e sugestão), a indicação do assunto/tag e localização da situação - todos desafios e atividades primordiais para os relatórios gerenciais. Dessas indicações, o ouvidor consegue cruzar dados do tipo: no período $x$ houve $y$ reclamações sobre 0 assunto $z$, relacionado à área $a$, ou mesmo que, no período $x$, os assuntos mais apontados enquanto denúncia foram $b, c$ e $d$.

Como exemplo apresenta-se os resultados gerais do ano de 2019 gerados a partir das manifestações em toda a rede de ouvidorias da EBSERH, assim como os dados isolados da ouvidoria do hospital universitário da Universidade Federal do Maranhão (UFMA), campo de observação participante desta pesquisa. Aponta-se ainda que tais informações são advindas do Painel Resolveu, coordenado pela CGU.

Figura 1: Painel Resolveu - Rede de Ouvidorias EBSERH

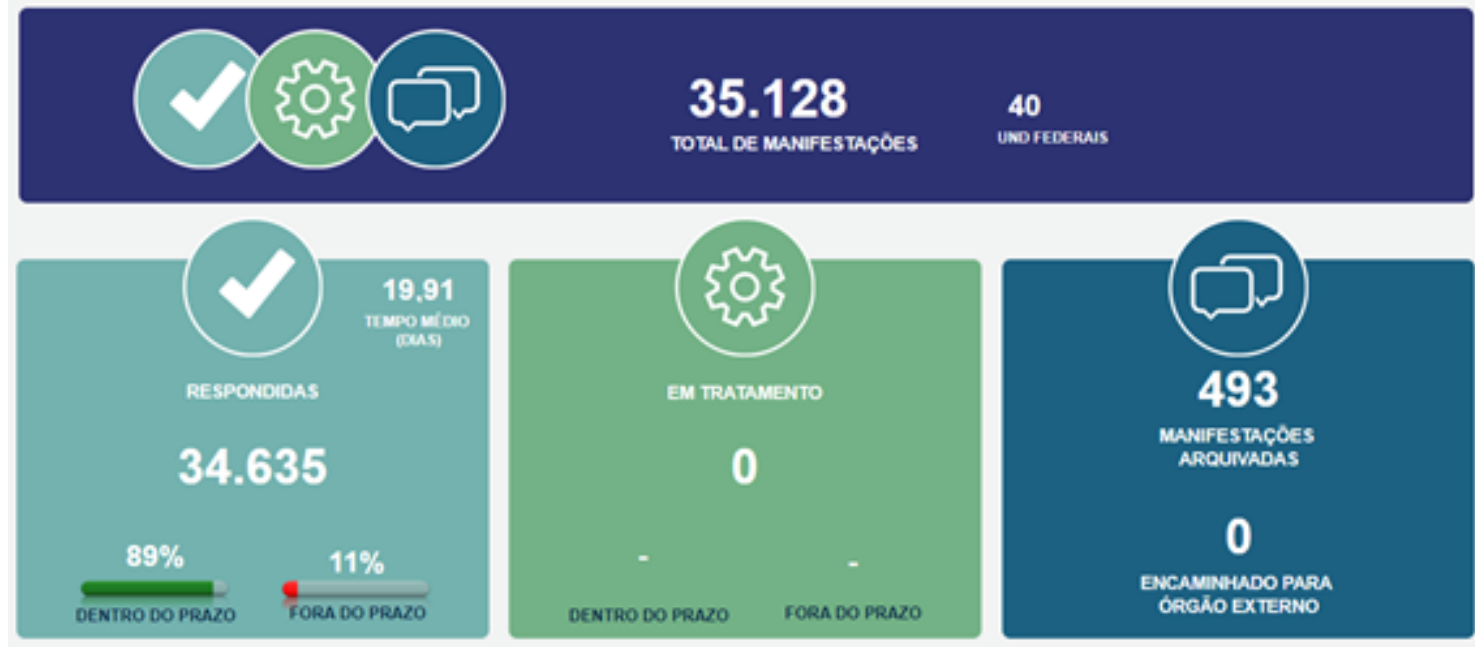

Fonte: CGU, 2020. 
Figura 2: Painel Resolveu - HU-UFMA

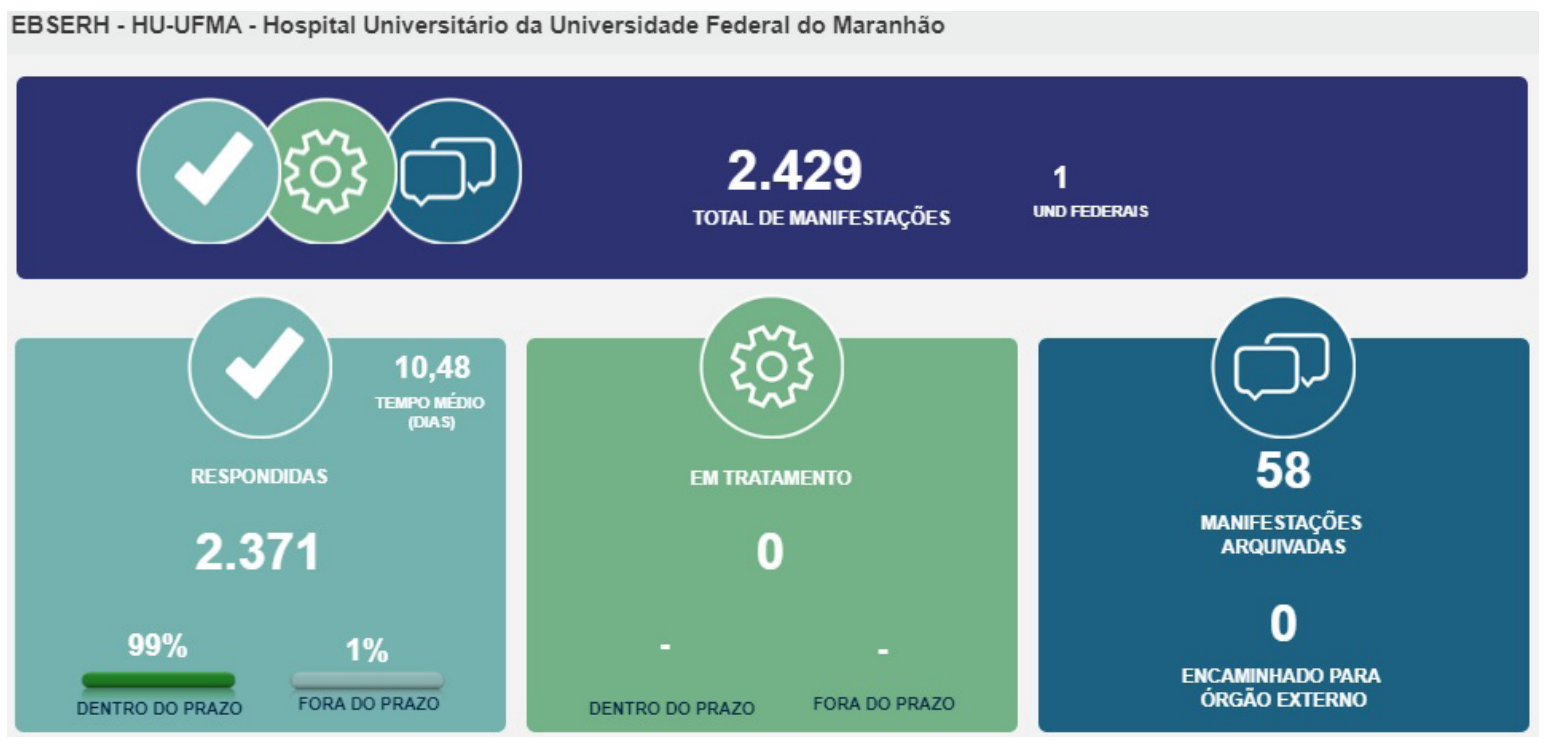

Fonte: CGU, 2020.

A pesquisa de satisfação, regulamentada por legislação, amparam a ouvidoria como se fossem braços, sendo uma forma dos usuários opinarem sobre o serviço prestado por meio de questionários enviados a eles. Nessa situação, a instituição vai em busca dos usuários, e não o contrário.

Obter um diagnóstico por meio de pesquisa sustenta e embasa possíveis planos de ação capazes de dirimir barreiras comunicacionais, favorecendo o fluxo informacional, a extinção de ruídos, o alinhamento de discurso e a percepção da imagem institucional gerada nos diversos públicos. Outrossim, os resultados obtidos por meio desse instrumento subsidiam tomadas de decisões gerenciais que favorecem os processos de trabalho pelo bem de todos os atores envolvidos, sejam funcionários, usuários, sociedade, instituições parceiras ou órgãos de controle.

Tal prática traz outros resultados que dão margem a relatórios gerenciais que beneficiam as melhorias contínuas das práticas assistenciais nos hospitais, uma vez que tem por objetivo medir a avaliação de pacientes/acompanhantes sobre os serviços ambulatoriais e de internação por meio de um questionário padrão estruturado com perguntas que avaliam os aspectos relacionados à estrutura, atendimento e avaliação geral do hospital.

A pesquisa é realizada sob a coordenação da ouvidoria geral, simultaneamente, em todos os hospitais universitários e, para sua execução, é lançado mão de um planejamento com identificação de população e amostra. Posteriormente, faz-se um teste no instrumento de coleta e a organização de escala de trabalho com base em estatísticas a fim de ser uma pesquisa representativa e, ao mesmo tempo, aleatória, minimizando os vieses e contando com a elaboração de estratégias de divulgação, o recrutamento de pessoal, a capacitação de equipe de pesquisadores, o acompanhamento da aplicação dos questionários, o controle de cada etapa do processo e a produção de relatório gerencial para apresentação dos dados à gestão.

Pensar esta pesquisa apenas como um instrumento que visa medir a satisfação é instrumental. Tal mecanismo, além de ser um diagnóstico situacional, ajuda o ouvidor a ser um gestor de comunicação, gerenciando um projeto específico em todas as suas etapas: planejamento, execução, acompanhamento e correção. Paralelamente, faz da ouvidoria um serviço com uma carga informacional enorme a partir do feedback dos usuários, o que é computado em um banco de dados substancial para tomadas de decisões com foco na melhoria contínua dos processos de trabalho.

De maneira geral, segue o resultado do último ciclo, com a indicação de todos os hospitais da rede EBSERH, que, juntos, ouviram 12.534 usuários, além dos dados específicos do hospital universitário da Universidade Federal do Maranhão (HU-UFMA), com a participação de 363 pessoas. 
Figura 3: Pesquisa de satisfação dos usuários pela rede de ouvidorias EBSERH - ciclo 2019
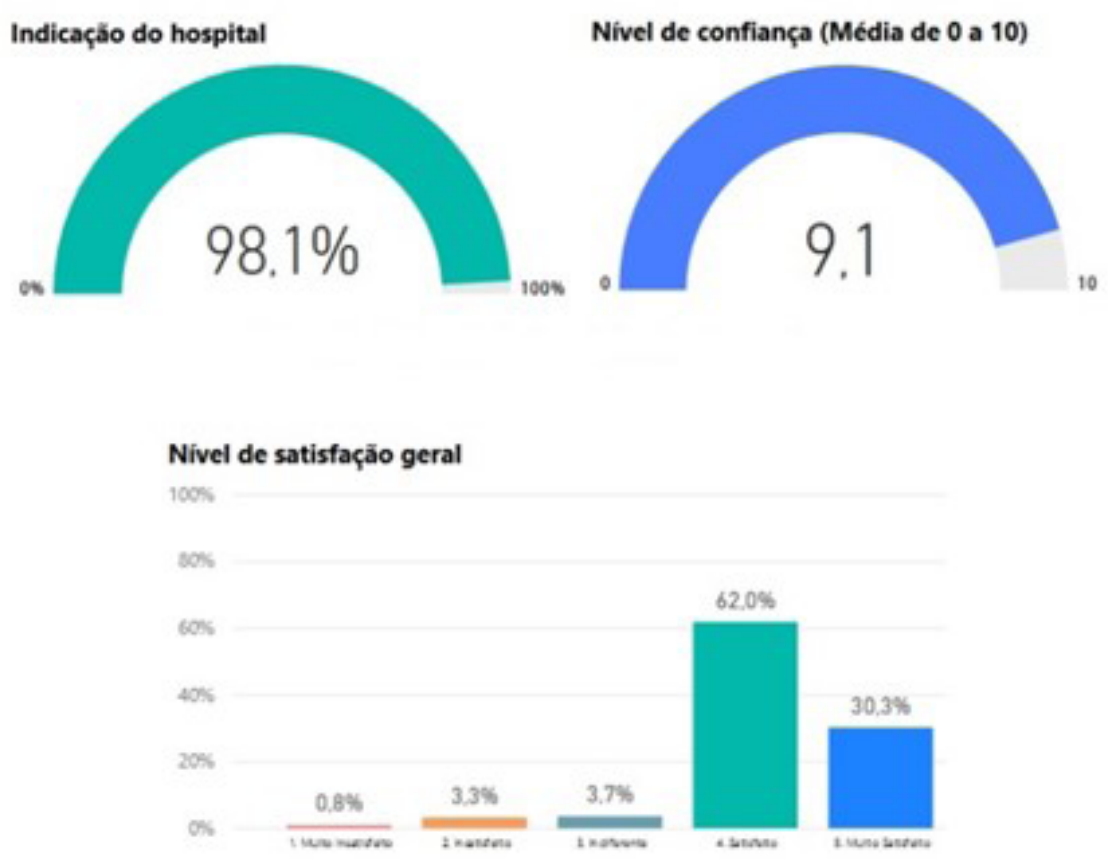

Fonte: EBSERH, 2019.

Figura 4: Pesquisa de satisfação dos usuários do HU-UFMA - ciclo 2019
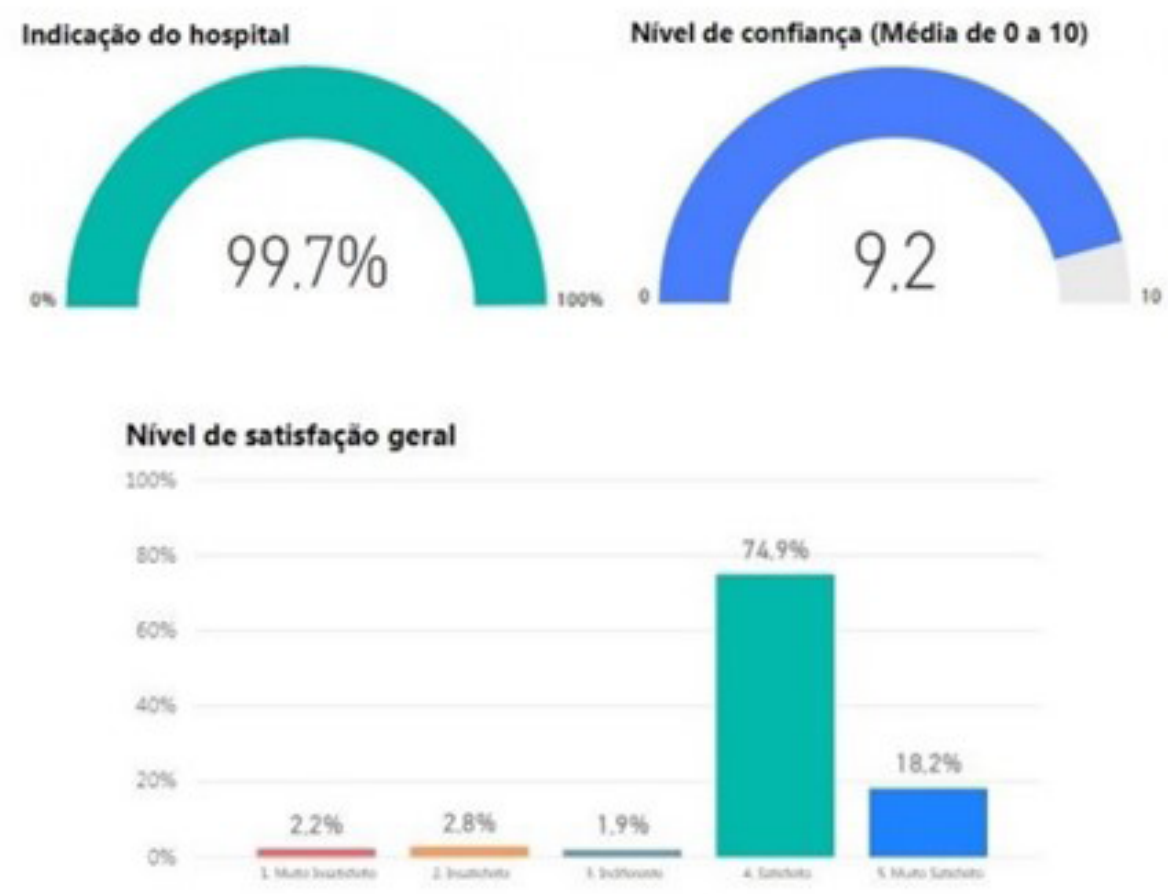

Fonte: EBSERH, 2019.

O Serviço de Informação ao Cidadão (SIC) é um instrumento da Lei no 12.527, de 18 de novembro de 2011, também conhecida como a Lei de Acesso à Informação (LAI). Por força da Portaria nำ153, de 21 de novembro de 2013, a EBSERH determinou que os ouvidores atuassem como gestores do SIC. Assim, o SIC torna-se as pernas da ouvidoria, sendo a sustentação da transparência e da publicização das informações institucionais, gerando valor ao processo de controle social e estabelecendo a garantia a esse direito fundamental com acesso quase irrestrito, além de atender e orientar os usuários quanto ao dia a dia dos hospitais.

Tal atividade é importante para fazer com que a gestão aprimore constantemente a prática da disponibilização de informações públicas para a sociedade de acordo com a legislação. Pela ouvidoria, qualquer cidadão pode requerer uma informação pública à instituição. Basta acessar o e-SIC (sistema eletrônico) e cadastrar o pedido. 
Ao receber um desses pedidos, a ouvidoria analisa a solicitação e deve responder de imediato caso esteja de posse dela. Não tendo conhecimento daquilo que é requerido, deve-se encaminhar à área competente para que haja um posicionamento referente ao pedido, respeitando o prazo estabelecido. Esse processo assemelha-se ao de recebimento, análise, cadastro, encaminhamento, monitoramento e reposta ao usuário a partir de uma demanda da ouvidoria.

No entanto, inúmeras informações outrora não divulgadas "tornaram-se" públicas com a Lei no 12.527 . Para tanto, a Controladoria Geral da União (CGU) listou um hall de tipos de informações a serem disponibilizadas pelas instituições públicas em suas páginas na internet, a exemplo: receitas e despesas, auditorias, licitações e contratos, quem é quem, informações classificadas, entre outros.

Essas informações são gerenciadas pela ouvidoria de cada instituição, que monitora e avalia a disponibilização e atualizações periódicas das informações, coordenando práticas e orientando as diversas áreas na produção sistemática delas com o apoio do setor de comunicação para a devida publicização.

Assim, o ouvidor é partícipe desse processo e deve atuar para que tais informações estejam à disposição da sociedade, justamente sob a perspectiva da transparência pública.

A título de exemplificação, a seguir é disposto o número de pedidos de acesso no ano de 2019.

Figura 5: Painel "Lei de Acesso à Informação" da rede de ouvidorias EBSERH - 2019
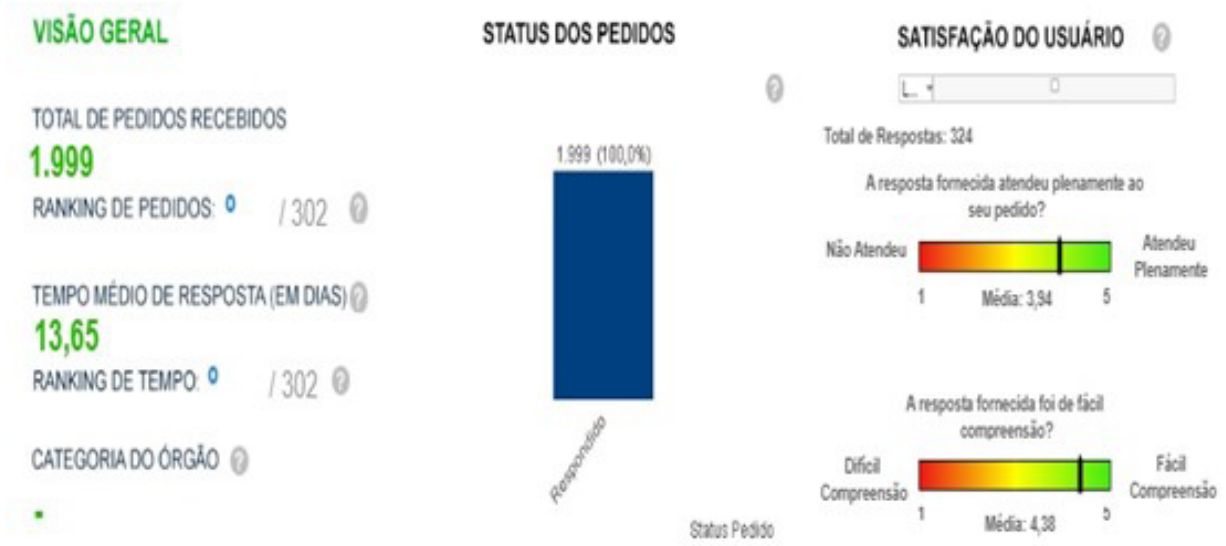

Fonte: CGU, 2020.

Figura 6: Painel "Lei de Acesso à Informação" do HU-UFMA

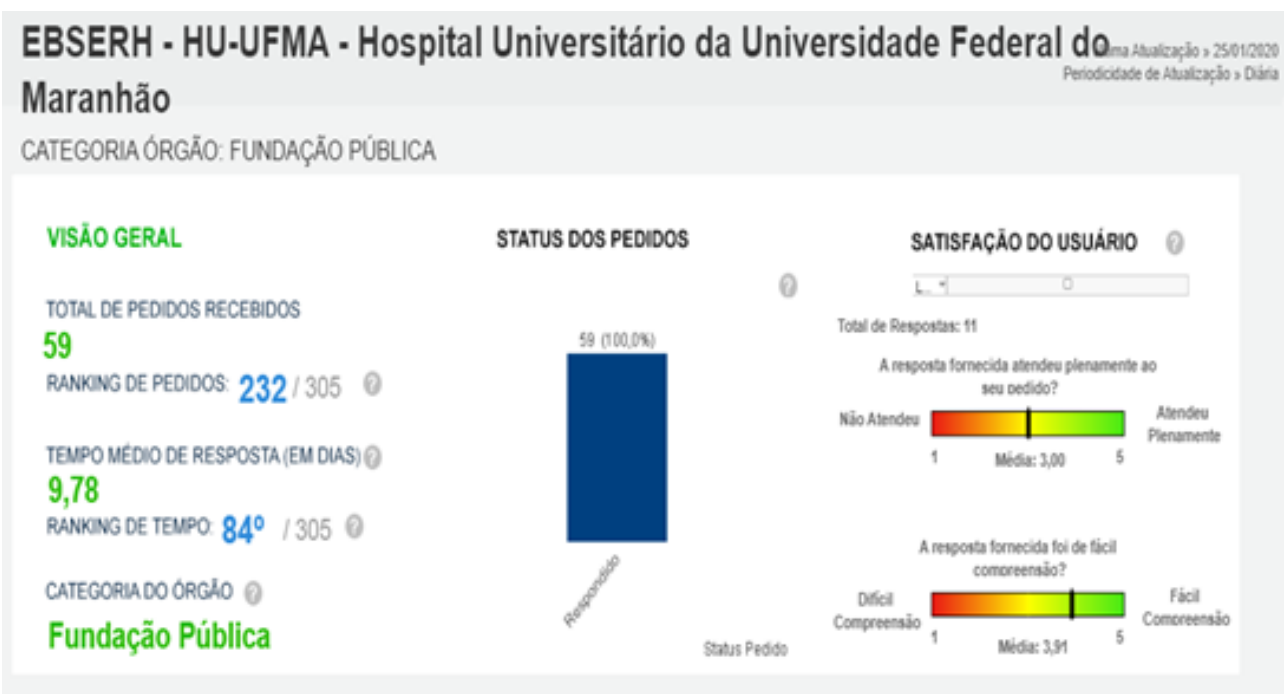

Fonte: CGU, 2020. 
Da tríade indicada, percebe-se que práticas comunicativas são estabelecidas a partir das vozes dos vários "eus" - seja em registro de manifestação, quando um usuário utiliza a ouvidoria para falar com a instituição; durante a pesquisa de satisfação, avaliando os serviços ou indicando situações para possíveis melhorias e ou potencialização de ações; ou em uma solicitação de informação pública.

Nota-se que a gestão pode extrair inúmeras informações que subsidiam decisões gerenciais e até mesmo sirvam de prestação de contas para os órgãos de controle e para a sociedade, considerando o controle social e institucional.

Dessa mesma tríade, outras práticas comunicativas podem ser estabelecidas; no entanto, faz-se necessário compreender como essas práticas são percebidas pelos ouvidores sob a perspectiva das atividades desenvolvidas - que podem ser vistas pela ótica da comunicação organizacional, que favorece o desenvolvimento de um manual de comunicação para as ouvidorias da rede EBSERH.

\section{CONSIDERAÇÕES FINAIS}

A comunicação vem sendo discutida atualmente pela perspectiva do outro, buscando o fator humano para o desenvolvimento das atividades da área. Há a preocupação com todos os envolvidos nos processos comunicativos, sendo criados mecanismos de voz ativa àqueles que não eram percebidos ou não tinham forças ou formas de escuta em suas falas.

As instituições públicas vêm se preocupando não somente com os seus colaboradores, mas com todos os sujeitos organizacionais, sobretudo com aqueles que recebem os serviços prestados - ouvindo seus anseios, desejos de mudanças, críticas, avaliações, opiniões e, também, seus agradecimentos. Os vários "eus" têm, atualmente, a possibilidade de dialogar com as organizações por meio das ouvidorias, repartição propulsora do fator relacional e de mediação, caracterizada pelo ouvir e compreender os diversos usuários, reconhecendo-os como detentores de direitos e deveres para que suas expectativas sejam qualificadas, buscando sempre uma resposta conclusiva às suas demandas.

Esta pesquisa parte da ideia de que a ouvidoria pública é participação social, é comunicação e, também, é ferramenta de gestão. Tem potencial para fazer parte da gestão estratégica da comunicação como um componente da comunicação organizacional por meio da representatividade cidadã, fazendo com que inúmeras informações possam ser extraídas subsidiando decisões gerenciais e, até mesmo, servindo de prestação de contas para os órgãos de controle e para a sociedade, considerando 0 controle social e institucional.

Portanto, a proposta do manual está sedimentada no ato de padronização, enquanto rede, das práticas comunicativas das ouvidorias da EBSERH, com a finalidade de que haja uma similitude de vivência em cada hospital, respeitando a política de comunicação da empresa e as características dos hospitais universitários.

\section{REFERÊNCIAS}

BALDISSERA, Rudimar. (2008). Por uma compreensão da comunicação organizacional. In: SCROFERNEKER, Cleusa Maria Andrade (org.). O diálogo possível: comunicação organizacional e paradigma da complexidade. Porto Alegre: EDUPUCRS, 2008. p. 31-50.

BASTOS, Ana Rafaela; MARCHIORI, Marlene; MORAES, Mayna Marchiori de.A ouvidoria como processo de construção de conhecimento. In: IASBECK, Luiz Carlos Assis (org.). Ouvidoria: mídia organizacional. Porto Alegre: Sulina, 2012. p.78-94. 
BERNARDO, Danylo Santos. Evolução na comunicação: estudos nas redes sociais. 2011. Projeto de pesquisa (Mestrado em Comunicação) - Universidade Municipal de São Caetano do Sul, São Caetano do Sul, 2011. Disponível em: https://www.uscs.edu.br/ pesquisasacademicas/images/pesquisas/danylo_elias.pdf. Acesso em: 3 dez. 2019.

BRASIL. [Constituição (1988)]. Constituição da república federativa do Brasil de 1988. Brasília, DF: Senado federal, 1988. Disponível em: http://www.planalto.gov.br/ccivil_03/constituicao/constituicao.htm. Acesso em: 4 nov. 2019.

BRASIL. Lei n¹2.527, de 18 de novembro de 2011. Regula o acesso a informações previsto no inciso XXXIII do art. 5ํ…]. Diário Oficial da União, Brasília, DF, edição extra, p.1, 18 nov. 2011. Disponível em: http://www.planalto.gov.br/ccivil_03/_ato20112014/2011/Lei/l12527.htm. Acesso em: 27 dez. 2019.

BRASIL. Lei nำ13.460, de 26 de junho de 2017. Dispõe sobre participação, proteção e defesa dos direitos do usuário dos serviços públicos da administração pública. Diário Oficial da União, Brasília, DF, p. 4, 27 jun. 2017. Disponível em: http://www.planalto. gov.br/ccivil_03/_ato2015-2018/2017/lei/l13460.htm. Acesso em: 10 nov. 2019.

BRASIL. CGU - Controladoria Geral da União. Orientações para implantação de uma unidade de ouvidoria: rumo ao sistema participativo. Brasília, DF: Ascom/CGU, 2012. Coleção OGU.

BRASIL. CGU -Controladoria Geral da União. Painel resolveu? Controladoria Geral da União, Brasília, DF, 4 out. 2018. Disponível em: http://paineis.cgu.gov.br/resolveu/index.htm. Acesso em: 25 jan. 2020.

BRASIL. CGU - Controladoria Geral da União. Painel lei de acesso à informação. Controladoria Geral da União, Brasília, DF, 1 maio 2019. Disponível em: http://paineis.cgu.gov.br/lai/index.htm. Acesso em: 25 jan. 2020.

CURVELLO, João José Azevedo. Estudos de comunicação organizacional: entre a análise e a prescrição. In: CONGRESSO BRASILEIRO DE CIÊNCIAS DA COMUNICAÇÃO, 25., 2002, Salvador. Anais [...]. Salvador: Universidade do Estado da Bahia, 2002. Disponível em: http://www.portcom.intercom.org.br/pdfs/35000eb4dc54ecb792613fbeacf2f50e.pdf. Acesso em: 01 jan. 2020.

DESLAURIERS, Jean-Pierre; KÉRISIT, Michèle. 0 delineamento da pesquisa qualitativa. In: POUPART, Jean etal. A pesquisa qualitativa: enfoques epistemológicos e metodológicos. Petrópolis, RJ: Vozes, 2008. p.127-153. Coleção Sociologia.

EBSERH - Empresa Brasileira de Serviços Hospitalares. Painel de monitoramento da pesquisa de satisfação do usuário - PSU 2019. Microsoft Power BI, Redmond, [2019?]. Disponível em: https://app.powerbi.com/view?r= eyJrljoiYTJkYTMxZWMtZmM50SO0N214LThhYTUtOWRjY2lyM2MwMTZiliwidCI6ljYOZDMOZGRkLWFmZjAtNGQ5NS1iN2Yx LTA3MzRhNWM4NDVINSJ9. Acesso em: 19 jan. 2020.

EBSERH - Empresa Brasileira de Serviços Hospitalares. Portaria № 153, de 21 de novembro de 2013. Empresa Brasileira de Serviços Hospitalares, Brasília DF. Disponível em: https://www.ebserh.gov.br/sites/default/files/boletim-de-servico/2018-11/ boletim_servi\%25C3\%25A70_15_25112013.pdf. Acesso em: 19 jan. 2020.

FRANÇA, Vera Regina Veiga.Representações, mídias e práticas comunicativas. In: PEREIRA, Miguel; GOMES, Renato Cordeiro; FIGUEIREDO, Vera Lúcia Follain de (Orgs.). Comunicação, representação e práticas sociais. Rio de Janeiro: Editora PUC-Rio, 2005. 
IASBECK, Luiz Carlos Assis. Ouvidoria, lugar privilegiado de comunicação organizacional. In: CONGRESSO BRASILEIRO DE CIÊNCIAS DA COMUNICAÇÃO, 29., 2006, Brasília. Anais [...]. Brasília: Universidade de Brasília, 2006. Disponível em: http://www.portcom.intercom.org.br/pdfs/60879359549489645852967863883468496648.pdf. Acesso em: 5 out. 2019.

IASBECK, Luiz Carlos Assis. Ouvidoria é comunicação. Organicom, São Paulo, v.7, n.12, p.14-24, 2010. Disponível em: https://www.revistas.usp.br/organicom/article/view/139045. Acesso em: 5 out. 2019.

IASBECK, Luiz Carlos Assis. Ouvidoria: mídia organizacional. Porto Alegre: Sulina, 2012.

MANZATO, Antonio José; SANTOS, Adriana Barbosa. A elaboração de questionários na pesquisa quantitativa. Departamento de Ciência de Computação e Estatística - IBILCE. Universidade Estadual Paulista. São Paulo. Disponível em: http://www.inf.ufsc.br/ - vera.carmo/Ensino_2012_1/ELABORACAO_QUESTIONARIOS_PESQUISA_QUANTITATIVA.pdf. Acesso em: 27 dez. 2019.

MARCHIORI, Marlene Regina. Cultura e comunicação organizacional:um olhar estratégico sobre a organização. São Caetano do Sul: Difusão, 2006.

MARCHIORI, Marlene Regina. Ouvidoria interna como processo de interação nas organizações contemporâneas. Organicom, São Paulo, v.7, n.12, p.116-129, 2010. Disponível em: https://www.revistas.usp.br/organicom/article/view/139051/134399. Acesso em: 28 jan. 2019

MARTELETO, Regina Maria. Redes sociais, mediação e apropriação de informações: situando campos, objetos e conceitos na pesquisa em ciência da informação. Tendências da Pesquisa Brasileira em Ciência da Informação, João Pessoa, v.3, n.1, p.27-46, 2010. Disponível em: http://www.brapci.inf.br/index.php/res/v/119365. Acesso em: 2 dez. 2019.

NASSAR, Paulo.(2006). A comunicação organizacional na contemporaneidade. In: Revista Novos Olhares, São Paulo, Ano 9, n.17, p.33-40, 2006. Disponível em: http://www.revistas.usp.br/novosolhares/article/view/51423. Acesso em: 11 jan. 2019.

PERUZZO, Cecília Maria Krohling. Direito à comunicação comunitária, participação popular e cidadania. Lumina, Juiz de Fora, v.1, n.1, p.1-29, 2007. Disponível em: https://periodicos.ufjf.br/index.php/lumina/article/view/20989. Acesso em: 30 ago. 2019.

Artigo recebido em 27/04/2020 e aprovado em 08/10/2020. 